\title{
Jet lag and environmental conditions that may influence exercise performance during the 2010 FIFA World Cup in South Africa
}

MP Schwellnus MBBCh, MSc(Med) Sports Science, MD(Sports and Exercise Medicine), FACSM, FFIMS \& EW Derman MBChB, PhD(Sports and Exercise Medicine), FACSM, FFIMS

To cite this article: MP Schwellnus MBBCh, MSc(Med) Sports Science, MD(Sports and Exercise Medicine), FACSM, FFIMS \& EW Derman MBChB, PhD(Sports and Exercise Medicine), FACSM, FFIMS (2010) Jet lag and environmental conditions that may influence exercise performance during the 2010 FIFA World Cup in South Africa, South African Family Practice, 52:3, 198-205, DOI: $10.1080 / 20786204.2010 .10873971$

To link to this article: http://dx.doi.org/10.1080/20786204.2010.10873971

\section{(c) 2010 SAAFP. Published by Medpharm.}

\section{Published online: 15 Aug 2014.}

Submit your article to this journal 지

Џll Article views: 114

Q View related articles $₫$ 


\title{
Jet lag and environmental conditions that may influence exercise performance during the 2010 FIFA World Cup in South Africa
}

Schwellnus MP, MBBCh, MSc(Med) Sports Science, MD(Sports and Exercise Medicine), FACSM, FFIMS Derman EW, MBChB, PhD(Sports and Exercise Medicine), FACSM, FFIMS UCT/MRC Research Unit for Exercise Science and Sports Medicine, Department of Human Biology, University of Cape Town , International Olympic Committee (IOC) Research Center Correspondence to: Prof Martin Schwellnus, e-mail: martin.schwellnus@uct.ac.za Keywords: soccer; performance; travel; jet lag; environment; heat; cold; pollution; allergy

\begin{abstract}
The 2010 FIFA World Cup will be held in South Africa in June/July 2010. This is the largest international sports event ever to be held in this country. At this time 32 international football teams, with their management and supporters, will travel to South Africa. These players and visitors will be exposed to changes in time zones (those travelling from continents in the East and West) as well as different environmental conditions. In particular, for the players, the achievement of peak sporting performance during this event is most important. It is well established that, in order to achieve peak exercise performance, many variables need to be optimised. These variables include physical and mental training, rest, nutrition, team dynamics and tactics. However, adjustments to differences in time zones as well as environmental factors on and around the playing field can also have a significant impact on exercise performance. In this review, the potential effects of "jet lag", as well as several important environmental conditions, on exercise performance will be discussed. The climatic, atmospheric and weather conditions that are likely to be prevalent in each of the South African host cities at the time of the 2010 FIFA World Cup will be reviewed. Finally, practical recommendations to deal with the effects of jet lag, as well as guidelines to optimise performance under different environmental conditions that are expected during the 2010 FIFA World Cup, will be provided.
\end{abstract}

SA Fam Pract 2010;52(3): 198-205

\section{The effects of crossing multiple time zones on sports performance}

\section{Introduction}

In recent years there has been a large increase in the number of international sports competitions. In part, this has been made possible through the development of an efficient intercontinental air travelling network worldwide. Athletes are required to travel to international competitions all over the globe. In June 2010, 32 football teams will assemble in South Africa for the 2010 FIFA World Cup. These players will be spending long hours of travelling in a North-South direction or crossing multiple time zones travelling in an East-West direction, or a West-East direction. The aim of this article is to discuss the potential effects of travelling across multiple time zones on sports performance. Practical recommendations will be given to cope with the effects of jet lag. These recommendations are also applicable to recreational travellers and to the support staff for travelling athletes.

It is widely recognised that travelling across many time zones is associated with a syndrome characterised by general malaise together with a host of other nonspecific symptoms. ${ }^{1}$ This syndrome, known as the "jet lag" syndrome, ${ }^{2}$ may have a detrimental effect on sports performance. ${ }^{1}$ It is important for any health professional that deals with the travelling athlete to be aware of the potential negative effects of intercontinental travel on sports performance.

\section{The physiology of jet lag}

Jet lag is a transient clinical syndrome that occurs in response to a disruption of normal biological rhythms and classically results in non-specific symptoms (Table I). The syndrome develops in most individuals when they travel across three or more time zones. The syndrome is characterised by two phases: i) the development of circadian dysrhythmia (desynchronisation), and ii) adaptation to the new time zone (resynchronisation). An understanding of the basic physiology of these two phases is essential to give suitable guidelines to athletes and patients for the prevention of jet lag. 
Table I: General symptoms of jet lag²

- General malaise
- Headaches
- Insomnia
- Fatigue
- Lethargy
- Irritability
- Dizziness
- Non-specific gastrointestinal distress
- Reduced appetite
- Poor mental and psychological task performance

\section{Circadian dysrhythmia}

It is now fairly well established that jet lag is due to circadian dysrhythmia. Circadian dysrhythmia refers to the disruption (desynchronisation) of the normal biological clock (circadian rhythms) by external cues (light/dark cycles). ${ }^{2}$ Circadian rhythms are characterised by an inherent periodicity of 2426 hours and exist in a number of physiological systems in the body. They function as internal time indicators for the body and are important in the normal regulation of physical and psychological parameters such as body temperature, blood cortisol levels, and alertness (sleep/wake cycle). These normal rhythms are influenced by external cues in the environment, in particular light/dark cycles.

\section{Resynchronisation}

If an athlete crosses several time zones, the circadian rhythms that are controlled by the external cues of the previous time zone have to adjust to the external cues of the new time zone. This adjustment is known as resynchronisation and correlates with the resolution of the symptoms of jet lag. A number of factors can influence the period required for resynchronisation (Table II). ${ }^{1-4}$

Table II: Factors affecting resynchronisation

- Number of time zones crossed
- - Individual variation
- Age
- Exposure to sunlight in the new environment
- Physical exercise
- Diet
- Melatonin
- Other drugs (chronobiotics)

It is well established that the larger the number of time zones crossed, the longer it takes to resynchronise the circadian rhythms. A rule of thumb is that it takes approximately one day per time zone crossed to resynchronise. The direction of the flight also has an important bearing on the time taken to adjust. A North-South flight does not cross time zones and no adjustment of circadian rhythms is therefore required. It is well established that the time to adjust is $30-50 \%$ less if the flight is in an East-West direction (phase delay) compared to a West-East direction (phase advance). This difference is because the natural rhythm of the body is approximately 25 hours long, which makes it easier to adjust to conditions that lengthen the day (East-West flights).

There is a difference in the adjustment time of individuals. "Night persons", usually extroverts, have their peaks in circadian rhythms later in the day and will therefore adjust easier to West-East flight (phase advance). Conversely, "day people", usually introverts, will adjust easier to EastWest flights (phase delay).

Age is associated with a change in the normal sleep pattern. Usually this change involves going to bed earlier and rising earlier. This behaviour would therefore favour adjustment to West-East travel. The time to adjustment is also greatly influenced by how quickly the person is exposed to new environmental cues, in particular sunlight. Early exposure to the new night/day cycle results in a more rapid resynchronisation. Minor factors that can influence the resynchronisation time include the type and content of meals, as well as drugs known as chronobiotic drugs.

The effects of chronobiotic drugs on resynchronisation require further discussion. None of the drugs that are discussed have been studied in actual flight experiments in humans. However, there may well be a future role for chronobiotic drugs in the prevention of jet lag. There are two basic mechanisms by which drugs can affect the resynchronisation process.

Firstly, drugs can act as external cues or synchronisers of the biological rhythms. Examples of drugs that fall into this first category are adrenocorticotropic hormone (ACTH), levadopa, and parachlorophenylalanine. The timing of administration of these drugs in the normal cycle is crucial in determining their effects. If they are administered early in the cycle, they cause an advance in the normal cycle and will therefore assist athletes that are travelling in a WestEast direction (phase advance). Conversely, if they are administered later in the normal cycle, they delay the cycle and will assist athletes travelling in an East-West direction (phase delay).

The second mechanism by which chronobiotic drugs act is to intensify the effects of normal external cues. Drugs such as lithium and clorgyline facilitate resynchronisation after East-West flights. Tricylic anti-depressants, melatonin and oestradiol are drugs that are postulated to facilitate resynchronisation after West-East flights.

The chronobiotic drug melatonin deserves further discussion. ${ }^{3}$ This is a common drug used by athletes to adapt to time zone changes. Melatonin is secreted from the pineal gland between $21 \mathrm{~h} 00$ and $07 \mathrm{~h} 00$ and is regarded as a "dark pulse". Therefore, melatonin capsules taken in the evening (in the few days before departing at local time), and in the evening for a few days after arrival (at local time), may well facilitate resynchronisation. Taken in this manner, melatonin 
has been shown to reduce the symptoms of jet lag in both males and females, and in both travel directions (West to East and East to West). However, the exact mechanism by which melatonin may facilitate resynchronisation has not been established. A recent publication indicated that melatonin ingestion could alter the body clock. The use of melatonin by athletes specifically has not been well studied. In particular the effect of melatonin on exercise performance has not been documented.

It must also be mentioned that circadian rhythms of different systems resynchronise at different rates. For instance, body temperature, which varies from $36^{\circ} \mathrm{C}$ early in the morning to $38.5^{\circ} \mathrm{C}$ in the late afternoon, resynchronises at a relatively rapid rate (40-50 minutes per day). This is of particular importance for this discussion because the body temperature circadian rhythm has been shown to be the most important rhythm determining athletic performance. Hormonal and renal function rhythms on the other hand can take longer to adjust to new time zones.

\section{The effects of jet lag on sports performance}

There is substantial anecdotal but less scientific evidence that jet lag adversely affects sports performance. ${ }^{1}$ It has been shown that West-East travel across six time zones resulted in a decrease in athletic performance of approximately $10 \%$. Decreases in athletic performance for specific events were as follows: $270 \mathrm{~m}$ sprint (8-12\%), $2.8 \mathrm{~km}$ run (8-9\%), isokinetic muscle strength $(6-11 \%)$, and isokinetic muscle endurance (13\%).

\section{Practical guidelines to travelling athletes}

The most important purpose for writing this section is to provide the practitioner with practical guidelines to minimise the effects of jet lag in athletes or other patients that travel across time zones. ${ }^{1,2}$ The guidelines differ depending on one of two circumstances: i) travelling that involves small (less than three time zones) but consecutive time shifts, and ii) travelling that involves one large (more than three time zones) time shift. These practical guidelines are derived from the understanding of the basic physiology of the jet lag syndrome and are presented in Tables IIla and IIIb respectively.

Table III: Practical guidelines to minimise the effects of jet lag

\section{Small but consecutive time zone shifts}

- Schedule competitions in the morning after Westward flights and in the evening after Eastward flights

- Travel in one direction when competing at different venues on an extended trip

- Indulge in social and exercise activity (training sessions) immediately after arriving at the destination

- Preset the sleep/wake cycles to that of the destination a few days before departing
- Eat meals regularly after arriving at the destination

- Avoid alcohol during the flight

A single large time zone shift

- Arrive at the destination at least one day early for each time zone crossed (allow 14 days for resynchronisation if the time zone difference is greater than six hours)

- For flights crossing more than 10 time zones, it is better to take a West-East flight

- Attempt to partially synchronise sleep/wake cycles and meals a few days before departing (for East-West flights this means going to bed later)

- Indulge in social and exercise activity (training sessions) immediately after arriving at the destination

- Maintain regular sleeping and eating times upon arrival

- Alter light/heavy meals for three days before the flight

- Avoid alcohol during the flight

- Chronobiotic drugs and melatonin may be used

\section{Selected environmental conditions and exercise performance considerations}

As mentioned, the 2010 FIFA World Cup will take place in South Africa in June/July 2010. A number of environmental conditions will be present during that time, and these may negatively affect exercise performance. Specifically, environmental issues such as temperature, allergens, atmospheric pollution and ultraviolet radiation may affect the preparation strategies and performance of players. In this section, the potential effects of the environmental conditions on exercise performance will be briefly reviewed. Practical considerations to reduce the potential negative effects of these environmental conditions on performance and the health of players will be included.

\section{Temperature}

At the time of the 2010 FIFA World Cup (June/July) it will be winter in South Africa. Winter in South Africa is characterised by day-time temperatures ranging from $17^{\circ} \mathrm{C}$ to $23^{\circ} \mathrm{C}$ and night-time temperatures between $-2^{\circ} \mathrm{C}$ and $11^{\circ} \mathrm{C}$. Therefore, the effect on performance of low (hypothermic) rather than high (hyperthermic) temperatures will need to be considered. However, for the purposes of this review, the potential effects of both hyperthermia and hypothermia on exercise performance will be briefly discussed.

\section{Exercise performance and hyperthermia}

As ambient temperature rises above $20^{\circ} \mathrm{C}$, the bulk of heat dissipation in the exercising athlete results from the evaporation of sweat., 5 Significant fluid loss may have a negative effect on cardiovascular capacity and thermoregulatory function particularly in endurance exercise. $^{7,8}$ However, some degree of fluid deficit is tolerable without any adverse effect on physiological function or exercise capacity. In shorter events, there may 
be no reduction in functional capacity in hot environments, ${ }^{7}$ however it is still prudent to maintain fluid balance. Any factor that limits evaporation such as high humidity or dehydration (greater that a 2-3\% decrease in pre-exercise body mass) may have effects on physiological function and athletic performance. ${ }^{5}$ The most widely used index for measuring heat stress is the wet bulb globe temperature (WBGT) index ${ }^{9}$ :

WBGT $=\left(0.7 \mathrm{~T}_{\mathrm{wb}}\right)+\left(0.2 \mathrm{~T}_{\mathrm{g}}\right)+\left(0.1 \mathrm{~T}_{\mathrm{db}}\right)$

where $T_{w b}$ is the wet bulb temperature, $T_{g}$ is the black globe temperature and $T_{d b}$ is the shaded dry bulb temperature. ${ }^{9}$

The risk of heat illness due to environment stress can be determined as using the WBGT index (Table IV) ${ }^{8,9}$ :

Table IV: The risk of heat illness according to the WBGT index

\begin{tabular}{l|l|}
\hline Risk & WBGT index \\
\hline Very high risk & WBGT $>28^{\circ} \mathrm{C}$ \\
\hline High risk & WBGT $23^{\circ} \mathrm{C}-28^{\circ} \mathrm{C}$ \\
\hline Moderate risk & WBGT $18^{\circ} \mathrm{C}-23^{\circ} \mathrm{C}$ \\
\hline Low risk & WBGT $<18^{\circ} \mathrm{C}$ \\
\hline
\end{tabular}

\section{Exercise performance and hypothermia}

Clinically, hypothermia is defined as a core temperature below $35^{\circ} \mathrm{C}$ (i.e. a $\sim 2^{\circ} \mathrm{C}$ drop in normal body temperature) and this develops when heat losses exceed heat production. ${ }^{10,11}$ Athletes exercising in rainy weather can lose considerable body heat even in relatively mild temperatures, due to the greater convective capacity of water when compared with air. Thermal balance during exposure to cold and wet conditions depends on a complex interaction among factors including metabolic heat generated, exercise mode, anthropomorphic and clothing factors that insulate the body, and magnitude of cooling caused by water temperature, rain, and wind. ${ }^{10,11}$ At an air temperature of $5^{\circ} \mathrm{C}$, heat loss in wet clothes may be double what it would be in dry conditions. ${ }^{10}$ Furthermore, cold wind increases convective heat loss in proportion to wind speed i.e. wind chill factor. ${ }^{9}$ Exercise performed at intensities greater than $60 \% \mathrm{VO}_{2}$ max can maintain normal core temperature when the ambient temperature is $5^{\circ} \mathrm{C}$, clothes are completely wet and the wind is $5 \mathrm{~m} \cdot \mathrm{s}^{-1}$. However, when only light intensity exercise is performed ( $\leq 30 \% \mathrm{VO}_{2}$ max), heat losses exceed heat production, leading to declines in core temperature which may impact on exercise performance. ${ }^{10}$

A further possible consideration of exercise in cold environments is possible development of ExerciseInduced Bronchoconstriction (EIB), which is defined as a transient narrowing of the airways associated with exercise. Clinically, it is demonstrated by a $9-10 \%$ decrease in the forced expiratory volume in 1 second $\left(\mathrm{FEV}_{1}\right)$ which can limit maximal ventilation and thus impair maximal performance.
Exercise causes EIB in 80\% of people with asthma, but appears to have no effect on the lung function of normal subjects. ${ }^{12}$ Inhalation of cold and dry air during exercise has been implicated as a trigger for EIB in subjects with asthma.

\section{Temperature and exercise performance: practical considerations during the 2010 FIFA World Cup}

The expected environmental conditions at the time (June/ July) of the 2010 FIFA World Cup in the South African host cities are depicted in Table V. The risk of developing hypothermia during the 2010 FIFA World Cup is therefore low unless an extreme winter is experienced or the players engage in irresponsible behaviour. Bloemfontein is the only city to record average sub-zero temperatures at night (Table V), so the time of day that games are played may be a factor to consider in this host city. The lowest minimum temperature recorded between 1962 and 1990 was $-10^{\circ} \mathrm{C}$ in BloemfonteinBloemfontein (http://www.weathersa.co.za). The average daily minimum temperatures at the other host cities range from $4^{\circ} \mathrm{C}$ in Johannesburg and Polokwane to $11^{\circ} \mathrm{C}$ in Durban (Table V). Cold, wet and windy weather poses the greatest risk for developing hypothermia, particularly if the exercise intensity is not high enough to match body heat loss. ${ }^{13}$ These weather conditions are common in Cape Town and Port Elizabeth in winter, which experience the highest average rainfall and wind speeds (Table V). This, coupled with an average minimum temperature of $8^{\circ} \mathrm{C}$ in Cape Town and $9^{\circ} \mathrm{C}$ in Port Elizabeth, needs to be borne in mind when playing in these cities.

Hypothermia is best prevented by monitoring environmental temperature, wind, solar load, rain and altitude and by assessing the exercise regimen to be performed (e.g. intensity and duration), the clothing available and identifying those who might be at higher risk of getting hypothermia (e.g. experience and physical conditioning of the athlete, general health, and nutritional status). ${ }^{10,11}$ Cold weather clothing protects against hypothermia and peripheral cold injuries by air reducing heat loss through the insulation provided by the clothing and the trapped air within and between clothing layers. ${ }^{9,10}$ Mild or moderate hypothermia can be treated by replacing wet clothing with dry insulating material and warm fluids should be consumed. Individuals with moderate to severe hypothermia should be insulated in a blanket and taken to hospital immediately. ${ }^{9-11}$

The average daily maximum temperatures of the host cities range from $17^{\circ} \mathrm{C}$ in Johannesburg and Bloemfontein to $23^{\circ} \mathrm{C}$ in Durban and Nelspruit (Table V). These average temperatures are therefore unlikely to exceed the "moderate risk" WBGT index, and are not expected to impair performance. Fluid balance becomes a factor to monitor at temperatures above about $20^{\circ} \mathrm{C}$, when increased sweat rates cause an increase in body fluid loss. Although it is important to prevent dehydration during exercise in the 
Table V: Expected environmental conditions at the time of the 2010 FIFA World Cup in the host cities (June/July)

\begin{tabular}{|c|c|c|c|c|c|c|c|c|c|}
\hline & Bloemfontein & Cape Town & Durban & Johannesburg & Nelspruit & Port Elizabeth & Polokwane & Pretoria & Rustenburg \\
\hline $\begin{array}{l}\text { Position (latitude/ } \\
\text { longitude) }\end{array}$ & $\begin{array}{l}29^{\circ} 06^{\prime} \mathrm{S} \\
26^{\circ} 18^{\prime} \mathrm{E}\end{array}$ & $\begin{array}{l}33^{\circ} 59^{\prime} \mathrm{S} \\
18^{\circ} 36^{\prime} \mathrm{E}\end{array}$ & $\begin{array}{l}29^{\circ} 58^{\prime} \mathrm{S} \\
30^{\circ} 57^{\prime} \mathrm{E}\end{array}$ & $\begin{array}{l}26^{\circ} 08^{\prime} \mathrm{S} \\
28^{\circ} 14^{\prime} \mathrm{E}\end{array}$ & $\begin{array}{l}25^{\circ} 26^{\prime} \mathrm{S} \\
30^{\circ} 59^{\prime} \mathrm{E}\end{array}$ & $\begin{array}{l}33^{\circ} 59^{\prime} \mathrm{S} \\
25^{\circ} 36^{\prime} \mathrm{E}\end{array}$ & $\begin{array}{l}23^{\circ} 52^{\prime} \mathrm{S} \\
29^{\circ} 27^{\prime} \mathrm{E}\end{array}$ & $\begin{array}{l}25^{\circ} 44^{\prime} \mathrm{S} \\
28^{\circ} 11^{\prime} \mathrm{E}\end{array}$ & $\begin{array}{l}25^{\circ} 40^{\prime} \mathrm{S} \\
27^{\circ} 15^{\prime} \mathrm{E}\end{array}$ \\
\hline Altitude (m) & 1,351 & 42 & 8 & 1,694 & 671 & 60 & 1,230 & 1,330 & $\pm 1,400$ \\
\hline Sunrise (30 June) & $07 \mathrm{~h} 10$ & 07h52 & $06 h 52$ & $06 h 56$ & $\pm 06 h 52$ & 07h24 & $\pm 06 \mathrm{~h} 52$ & 06h54 & $\pm 07 \mathrm{~h} 03$ \\
\hline Sunset (30 June) & $17 \mathrm{~h} 28$ & $17 \mathrm{~h} 48$ & $17 \mathrm{~h} 07$ & $17 \mathrm{~h} 28$ & $\pm 17 \mathrm{~h} 07$ & $17 \mathrm{~h} 19$ & $\pm 17 \mathrm{~h} 07$ & $17 \mathrm{~h} 27$ & $\pm 17 \mathrm{~h} 28$ \\
\hline $\begin{array}{l}\text { Minimum daily } \\
\text { temperature }\left({ }^{\circ} \mathrm{C}\right)\end{array}$ & -2 & 8 & 11 & 4 & 6 & 9 & 4 & 5 & 5 \\
\hline $\begin{array}{l}\text { Maximum daily } \\
\text { temperature }\left({ }^{\circ} \mathrm{C}\right)\end{array}$ & 17 & 18 & 23 & 17 & 23 & 20 & 20 & 20 & 20 \\
\hline Precipitation $(\mathrm{mm})$ & 12 & 93 & 39 & 9 & 10 & 62 & 5 & 7 & 13 \\
\hline Humidity (\%) & 56 & 78 & 70 & 49 & 63 & 71 & 55 & 47 & 57 \\
\hline Prevailing wind direction & SSW & N & NNW & NNW - NW & W & W & W \& ENE & $S$ & SW \\
\hline $\begin{array}{l}\text { Average wind speed } \\
\left(\mathrm{m} \cdot \mathrm{s}^{-1}\right)\end{array}$ & $0.5-2.5$ & 5.6 & $0.5-2.5$ & $3.5-5.6$ & $0.5-2.5$ & $0.5-2.5$ & $0.5-2.5$ & $0.5-2.5$ & $0.5-2.5$ \\
\hline Gust wind speed $\left(\mathrm{m}^{\left.-\mathrm{s}^{-1}\right)}\right.$ & $8.7-10.7$ & $>10.7$ & $>10.7$ & $8.7-10.7$ & $3.5-5.6$ & $>10.7$ & $5.6-8.7$ & $3.5-5.6$ & $3.5-5.6$ \\
\hline UV rating & & $<5$ MED & $<7$ MED & & & & & $<10 \mathrm{MED}$ & \\
\hline
\end{tabular}

Data sources: http://www.weathersa.co.za, http://www.routes.co.za/weather, http://www.timeanddate.com, http://www.environment.gov.za

heat, excessive drinking is also detrimental to performance and dangerous to health. Therefore it is recommended that athletes should not drink more than is necessary to satisfy thirst. Furthermore, each athlete responds differently to heat stress and therefore athletes should be monitored on an individual basis. ${ }^{7,9}$ This can easily be achieved by weighing the players before and after training and matches to ensure that changes in body mass are compensated for by fluid ingestion during the recovery phase.

The highest maximum daily temperature recorded between 1962 and 1990 was $36^{\circ} \mathrm{C}$ in DurbanBloemfontein (http:// www.weathersa.co.za). Under these unlikely but extreme conditions, the WBGT index in this host city may increase to the "high" risk or even the "very high risk" rating. Methods of pre-cooling have been investigated for their potential to reduce thermal strain and improve sports performance in extremely hot conditions such as this. However, the effectiveness and practicality of using many of the available methods remains inconclusive. ${ }^{14} \mathrm{~A}$ period of acclimatisation, of approximately 1-2 weeks, may assist the athlete to adapt to exercising in hot conditions by improving thermoregulatory responses. ${ }^{9}$ Acclimatisation has been shown to reduce physiological parameters such as heart rate, rectal temperature, blood lactate, and blood glucose concentrations that are increased in the heat. ${ }^{6}$ Immediate treatment of exertional heatstroke may include cool water immersion, application of wet towels and ice packs to the neck, under-arms and groin areas; all of which have been used successfully. ${ }^{9}$

\section{Allergens}

Athletes travelling to different geographical locations may be exposed to allergens (aeroallergens, contact allergens and food allergens). ${ }^{15,16}$ Allergens in the environment must therefore be considered during preparation and sports competitions as allergic conditions can impair sports performance. For the purposes of this brief review, mainly aeroallergens will be discussed, as these relate to environmental conditions.

The main allergy producing pollens are derived from the grasses. However, tree pollens are also important causes of symptomatic allergies. Pollen grains need to be smaller than 50 microns to be distributed by the wind. Pollen counts are established by expressing the number of pollen grains counted on each sample as a daily average in pollen grains per cubic meter of air based on a known rate of airflow through the pollen trap. Usually pollen counts of more than 50 grains per cubic meter indicate significant risk to allergy sufferers at rest, but patient sensitivity is extremely variable and many patients can develop allergic symptoms at lower pollen counts. ${ }^{17}$

During exercise, ventilation may increase up to 200 L. $\min ^{-1}$ for short periods of time in speed and power athletes and for longer periods in endurance athletes. When the ventilation level exceeds about 30 L. $\mathrm{min}^{-1}$, there is a shift from nose breathing to combined mouth and nasal breathing. This shift in breathing results in a greater deposition of airborne allergens and other inhaled particles to the lower airways. Exercise-induced bronchospasm (EIB) increases significantly during the pollen season in patients with asthma and who are allergic to pollen, but not in 
patients who are allergic to pollen but do not have asthma. ${ }^{18}$ Although some athletes experience improvement in allergic rhinitis with exercise, rhinitis may worsen with exposure to allergens, especially in cold or dry air. Allergic rhinitis has been shown to have negative effects on performance (ability to train and compete). ${ }^{19}$ Pollutants have also been shown to interact with allergens in inducing sensitisation and triggering of symptoms in allergic subjects. ${ }^{19}$ Finally, in susceptible individuals, contact with grasses and other allergens can result in urticaria (skin allergy).

\section{Allergies and exercise performance: practical considerations during the 2010 FIFA World Cup}

The main allergy producing pollens are derived from the grasses, but trees may also produce pollen which can cause symptoms. It may be important to test the players before the competition so that the susceptible players and the pollen causing the allergy can be identified and the players treated prophylactically. In South Africa grass species for testing for allergenicity can include the following: Lolium (Rye), Eragrostis (Boer Love grass), Cynodon dactylon (Bermuda grass), Zea mays (Maize), Pennisetum (Kikuyu grass), and Stenotaphrum secundatum (Buffalo grass).

In the Western Cape Province (Cape Town venue), mainly female Kikuyu strands are found. This is a reason for less allergenicity of this grass in the Cape compared to Gauteng and along the East Coast where male plants are abundant. ${ }^{17}$ Causes of tree pollenosis in the Gauteng and Mpumalanga areas include the Cypress, Willow, Ulmus and in the Coastal areas of KwaZulu-Natal Moracea (Mulberry) species produce the most abundant tree pollen in the spring. Tree pollens usually cause symptoms in well defined peaks between August and November, and symptoms are usually short lived. ${ }^{17}$ Grass pollens are abundant between September and February, with weed pollen concentrations being higher from March to May. Weeds are not thought to be as important in southern Africa, however English plantain (a perennial weed) occurs quite extensively in the Cape and is also an important cause of symptoms. ${ }^{17}$ Therefore, the high risk periods for allergies in South Africa are spring and summer rather than autumn and winter.

In a survey of South African Olympic athletes, it was found that Plane pollen allergy was present in about $15 \%$ of the athletes, followed by Oak pollen allergy. ${ }^{17}$ However, given the low concentrations of pollens during the months of June and July, the probability of allergic reactions compromising performance during the 2010 FIFA World Cup is unlikely. However, the general recommendations for the management of athletes with predispositions to allergy are depicted in Table VI.
Table VI: General recommendations for the management of athletes with predispositions to allergy

- Early recognition and diagnosis

- Allergy testing prior to competition (aeroallergens, trees and grasses)

- Recognition of associated or sub-clinical asthma through adequate pulmonary function tests

- Avoidance of exposure to relevant allergens and pollutants during exercise

- Medical treatment to improve allergic symptoms without affecting athletic performance while complying with anti-doping regulations ${ }^{19}$

\section{Atmospheric pollution}

A diverse mixture of suspended particles and gases containing reactive free radical species is released into the atmosphere as a consequence of fuel combustion..$^{20}$ Particulate matter (PM) pollution comprises solids and liquids that are present in the air in particles small enough to remain in suspension for some hours or days. ${ }^{21}$ The particles are classified according to aerodynamic diameter, as coarse $(<10 \mathrm{~mm}$; PM10), fine $(<2.5 \mathrm{~mm}$; PM2.5) or ultrafine $(<0.1 \mathrm{~mm}$; PM0.1) particles. Presently, the air quality standards for PM10 and PM2.5 in the United States and the United Kingdom are $50 \mathrm{mg} \cdot \mathrm{m}^{-3}$ and $15 \mathrm{mg} \cdot \mathrm{m}^{-3}$ respectively as a running 24 hour average..$^{20,21}$

Although athletes are at increased risk of inhaling pollutants, the question of pollutant deposition in the respiratory tract during exercise remains uncertain. ${ }^{21}$ Particulate matter associated with both $\mathrm{SO}_{2}$ and ozone may be deposited in the lower respiratory tract, producing an increase in respiratory symptom exacerbations and deterioration in lung function..$^{19}$ However, the impact of PM10 on athletic performance has not yet been determined. ${ }^{22}$ Given that PM10 induces oxidative stress and inflammation, further research is required to assess the impact of PM10, ultrafine particles and metals on respiratory and cardiovascular function in relation to sports performance..$^{22}$

Ozone $\left(\mathrm{O}_{3}\right)$ is generated from hydrocarbons and $\mathrm{NO}_{2}$ in the presence of ultraviolet radiation..$^{19} \mathrm{~A}$ concentration of 100 $\mathrm{ppb}$ causes decrements in lung function at an exercise intensity equating to a minute ventilation of $70 \mathrm{~L}$. $\mathrm{min}^{-1}{ }^{21}{ }^{21}$ but this is a very high concentration compared to the UK national limit of $50 \mathrm{ppb}$ (running 8 hour mean). ${ }^{21}$ Allergen responses may be exaggerated by ozone,$^{19}$ however there is high individual variability in response to $\mathrm{O}_{3}$ exposure. ${ }^{21}$ The respiratory discomfort associated with $\mathrm{O}_{3}$ exposure may cause decreases in maximal performance. ${ }^{21}$ Nitrogen dioxide $\left(\mathrm{NO}_{2}\right)$ is derived mainly from motor vehicles, power stations and industrial processes. There is little or no negative affect as a result of exposure to $\mathrm{NO}_{2}$ in normal subjects. Asthmatics have been shown to experience significant 
increases in exercise-induced bronchoconstriction (EIB) or cold air hyperventilation ${ }^{19}$ with short term $\mathrm{NO}_{2}$ exposures of $500 \mathrm{ppb}$ - however, $\mathrm{NO}_{2}$ levels in urban environments are usually below $150 \mathrm{ppb}^{21}$

Sulphur dioxide $\left(\mathrm{SO}_{2}\right)$ begins to affect lung function in normal healthy adults at concentrations between 1000 and 2000 $\mathrm{ppb}$. Thus, with the recommended air quality standard for $\mathrm{SO}_{2}$ being $100 \mathrm{ppb}$ (15 minute average), ${ }^{21}$ it is unlikely to be of concern to athletes with normal lung function. Asthmatics however, may be 10 times more sensitive to $\mathrm{SO}_{2}$ than nonasthmatics, especially when exercising. At concentrations of $500 \mathrm{ppb}$ exercising asthmatics experience significant changes in airways resistance after just five minutes of exercise, with wheezing, chest tightness, and dyspnoea being experienced. ${ }^{21}$ Air temperature and humidity influence the degree of symptoms experienced, with cold dry air producing a faster and more intense response than warm moist air. $^{21}$

Volatile organic compounds (VOCs) are a group of over 100 chemicals formed during incomplete burning of fuel and other organic substances, ${ }^{20}$ many of which are carcinogenic. ${ }^{21}$ There are therefore no safe levels recommended by the World Health Organization. The UK National Air Quality limits are $5 \mathrm{ppb}$ for benzene and 1 $\mathrm{ppb}$ for 1,3-butadiene (running annual mean). ${ }^{21}$ The area of exercise and the inhalation and possible accumulation of VOCs has received little attention. ${ }^{21}$

Athletes are at increased risk of inhaling pollutants because 1) with increases in minute ventilation during exercise there is an increase in the concentration of pollutants inhaled, 2) a larger fraction of air is inhaled through the mouth during exercise, thus bypassing normal nasal filtration mechanisms, and 3) the increased air- flow velocity carries pollutants deeper into the respiratory tract. ${ }^{20,21}$ Blood toxin levels may quickly reach harmful levels, as was shown in New York City runners after 30 minutes of exercise near busy roads. This evoked an acute rise in blood carboxyhaemoglobin levels from $1.7 \%$ to $5.1 \%$. These levels are similar to those found in regular cigarette smokers. During exercise low concentrations of pollutants $\left(\mathrm{O}_{3}\right.$ and $\left.\mathrm{NO}_{2}\right)$ were required to cause similar lung damage to that achieved by high concentrations of the same compounds at rest..$^{20}$

\section{Atmospheric pollution and exercise performance: practical considerations during the 2010 FIFA World Cup}

As mentioned, it has been documented that strenuous exercise in heavy traffic for 30 minutes can increase the level of carboxyhaemoglobin by 10 -fold and that is equivalent to smoking 10 cigarettes. Experimental evidence confirms the detrimental effect that carbon monoxide (CO) has on athletic performance. ${ }^{21}$ Hence it is prudent always to train away from traffic to avoid or minimise exposure to air-borne contaminants. There is an exponential decline in concentrations of many air pollutants with increasing distance from a busy road. The length of time spent exercising is another very important factor. Ultra-marathon runners and others participating in long endurance events - for example, walking and cycling - are likely to be most at risk from the negative and harmful effects of pollution exacerbated by exercise. ${ }^{20,21}$

\section{Ultraviolet radiation}

The depletion of the ozone layer is a critical environmental concern as it shields the earth from the sun's harmful ultraviolet (UV) rays (light of 290-400 nm in wavelength). Ozone depletion as well as seasonal and weather variations allow different amounts of UV radiation to reach the earth. The UV Index considers the ozone layer thickness, UV incidence (incoming radiation level) on the ground, cloud cover (clouds reduce UV levels) and altitude (UV levels increase by $6 \%$ for every $1 \mathrm{~km}$ of elevation gain). It does not include the effects of variable surface reflection (e.g. sand, water, or snow), atmospheric pollutants or haze, which may nearly double UV exposure strength. Thus, the UV Index, which ranks UV radiation levels on a 1-11+ scale, is a useful tool in assessing exposure risk. Another indicator (AC10 UV-B trends) reports the amount of UV-B measured as the minimum erythema dose (MED). The MED is the minimum amount of exposure required to produce a perceptible reddening of the skin. The World Meteorological Organisation (WMO) guidelines categorise measured UV-B exposure levels in terms of their seriousness of impact on humans. Ideally, UV-B exposures should not exceed 'moderate' at any time during the year.

\section{Ultraviolet radiation and exercise: practical considerations during the 2010 FIFA World Cup}

Exposure to the sun is associated with different types of skin cancer, accelerated skin ageing, eye diseases such as cataracts, and there is also evidence of reduced effectiveness of the immune system. Sun protection is therefore an important precaution that should be taken against UV radiation. Time spent in the sun during midday hours should be limited. Athletes should wear protective clothing such as a hat that shades the eyes, face and neck, as well as protective eyewear. A sunscreen that has a minimum sun protection factor of SPF $15+$ should be applied to exposed skin regularly. Measured UV-B exposure levels in Cape Town and Durban are moderate (<7MED) during winter, while Pretoria is high (7-14MED). According to the World Meteorological Organisation, UV-B exposures should not exceed 'moderate' at any time during the year. Therefore, the above precautionary measures should be taken in high-lying areas of South Africa, even during winter. 


\section{Summary: environmental conditions}

Knowledge of the environmental conditions expected at an upcoming competition is an important component of the preparation towards optimal performance at that competition. This review provides details of some important environmental conditions that are likely to be prevalent in the South African host cities at the time of 2010 FIFA World Cup. The potential effects of environmental conditions on exercise performance were reviewed. Cold, wet and windy weather can be expected in Cape Town and Port Elizabeth in winter. These factors, along with the exercise regimen to be performed in these conditions, should be monitored, and the appropriate clothing should be worn to avoid the risk of hypothermia. Given the low concentrations of tree, grass and weed pollens during the months of June and July in South Africa, the probability of allergic reactions compromising performance during the 2010 FIFA World Cup is unlikely. However, it is recommended that all players with a history of atopy be tested for the dominant pollens before the event to identify any player who may be susceptible and who therefore can be treated prophylactically. Precautions should always be taken against exposure to UV radiation.

\section{Acknowledgements}

The authors wish to recognise the contributions of $\mathrm{Dr}$ Jill Borresen, Dr Victor Ramathesele and Prof Mike Lambert in the preparation of an unpublished internal report on environmental issues during the 2010 FIFA World Cup. Some of the sections of this internal report, which was completed in 2007, were updated and included in this manuscript. Furthermore, some of the information in this manuscript was also presented by the first author at the FIFA Medical Symposium which was held at Sun City (South Africa) in February 2010.

\section{References:}

1. Reilly T, Waterhouse J, Edwards B. Jet lag and air travel: implications for performance. Clin Sports Med 2005;24(2):36780, xii.

2. Waterhouse J, Reilly $\mathrm{T}$, Atkinson $\mathrm{G}$. Jet-lag. Lancet 1997;350(9091):1611-1616.

3. Brown GM, Pandi-Perumal SR, Trakht I, Cardinali DP. Melatonin and its relevance to jet lag. Travel Med Infect Dis 2009;7(2):69-81.

4. Atkinson G, Edwards B, Reilly T, Waterhouse J. Exercise as a synchroniser of human circadian rhythms: an update and discussion of the methodological problems. Eur J Appl Physiol 2007;99(4):331-341.

5. Coris EE, Ramirez AM, Van Durme DJ. Heat illness in athletes: the dangerous combination of heat, humidity and exercise. Sports Med 2004;34(1):9-16.

6. Terrados N, Maughan RJ. Exercise in the heat: strategies to minimize the adverse effects on performance. J Sports Sci 1995;13 Spec No:S55-S62.

7. Maughan R, Shirreffs S. Exercise in the heat: challenges and opportunities. J Sports Sci 2004;22(10):917-927.

8. Armstrong LE, Casa DJ, Millard-Stafford M, Moran D S, Pyne S W, Roberts W O. Exertional Heat Illness during Training and Competition. ACSM Position stand. Med Sci Sports Exerc 2007;39(3):556-572.

9. Armstrong LE, Epstein Y, Greenleaf JE, et al. American College of Sports Medicine position stand. Heat and cold illnesses during distance running. Med Sci Sports Exerc 1996;28(12):i-x.

10. Castellani JW, Young AJ, Ducharme MB, Giesbrecht GG, Glickman E, Sallis RE. American College of Sports Medicine position stand: prevention of cold injuries during exercise. Med Sci Sports Exerc 2006;38(11):2012-2029.

11. Cappaert TA, Stone JA, Castellani JW, Krause BA, Smith D, Stephens BA. National Athletic Trainers' Association position statement: environmental cold injuries. J Athl Train 2008;43(6):640-658.

12. Weber TS. Environmental and infectious conditions in sports. Clin Sports Med 2003;22(1):181-196.

13. Nimmo M. Exercise in the cold. J Sports Sci 2004;22(10):898-915.

14. Quod MJ, Martin DT, Laursen PB. Cooling athletes before competition in the heat: comparison of techniques and practical considerations. Sports Med 2006;36(8):671-682.

15. Komarow HD, Postolache TT. Seasonal allergy and seasonal decrements in athletic performance. Clin Sports Med 2005;24(2):e35-50, xiii.

16. Hawarden D, Baker S, Toerien A, et al. Aero-allergy in South African olympic athletes. S Afr Med J 2002;92(5):355-356.

17. Potter PC. Understanding Pollenosis. SA Fam Pract 2003;45(7):29-34.

18. Helenius I, Haahtela T. Allergy and asthma in elite summer sport athletes. J Allergy Clin Immunol 2000;106(3):444-452.

19. Bonini S, Bonini M, Bousquet J, et al. Rhinitis and asthma in athletes: an ARIA document in collaboration with GA2LEN. Allergy 2006;61(6):681-692.

20. Sharman JE, Cockcroft JR, Coombes JS. Cardiovascular implications of exposure to traffic air pollution during exercise. QJM 2004;97(10):637-643.

21. Carlisle AJ, Sharp NC. Exercise and outdoor ambient air pollution. Br J Sports Med 2001;35(4):214-222.

22. Florida-James G, Donaldson K, Stone V. Athens 2004: the pollution climate and athletic performance. J Sports Sci 2004;22(10):967-980. 